\title{
Regulation of anoikis resistance by NADPH oxidase 4 and epidermal growth factor receptor
}

Hyeryeong Kim ${ }^{1,8}$, Jee Young Sung ${ }^{2,8}$, Eun-Kyung Park ${ }^{1}$, Seongho Kho ${ }^{1}$, Kyung Hee Koo ${ }^{1}$, Seog-Yun Park ${ }^{3}$, Sung-Ho Goh ${ }^{4}$, Yoon Kyung Jeon ${ }^{5}$, Sekyung Oh ${ }^{6}$, Byung-Kiu Park ${ }^{2}$, Yong-Keun Jung ${ }^{\star, 7}$ and Yong-Nyun Kim *,1

${ }^{1}$ Comparative Biomedicine Research Branch, Division of Cancer Biology, National Cancer Center, 323 Ilsan-ro, Ilsandong-gu, Goyang-si 410-769, Korea; ${ }^{2}$ Pediatric Oncology Branch, Division of Translational and Clinical Research II, National Cancer Center, 323 Ilsan-ro, Ilsandong-gu, Goyang-si 410-769, Korea; ${ }^{3}$ Department of Pathology, National Cancer Center, 323 Ilsan-ro, Ilsandong-gu, Goyang-si 410-769, Korea; ${ }^{4}$ Cancer Genomics Branch, National Cancer Center, 323 Ilsan-ro, Ilsandong-gu, Goyang-si 410769, Korea; ${ }^{5}$ Department of Pathology, Seoul National University College of Medicine, 28 Daehak-ro, Jongno-gu, Seoul 110-779, Korea; ${ }^{6}$ Department of Neurology and Neurological Sciences, School of Biological Science/Bio-Max Institute, Stanford University School of Medicine, Stanford, CA 94305, USA and 'School of Biological Science, Seoul National University, Gwanak-gu, Seoul 151-747, Korea

Background: Normal cells are sensitive to anoikis, which is a cell detachment-induced apoptosis. However, cancer cells acquire anoikis resistance that is essential for successful metastasis. This study aimed to demonstrate the function and potential mechanism of NADPH oxidase 4 (NOX4) and EGFR activation in regulating anoikis resistance in lung cancer.

Methods: Cells were cultured either in the attached or suspended condition. Cell viability was measured by cell counting and live and dead cell staining. Expression levels of NOX4 and EGFR were measured by PCR and immunoblotting. Reactive oxygen species (ROS) levels were measured by flow cytometry. Effects of NOX4 overexpression or NOX4 knockdown by si-NOX4 on anoikis sensitivity were explored. Levels of NOX4 and EGFR in lung cancer tissues were evaluated by IHC staining.

Results: NOX4 was upregulated but EGFR decreased in suspended cells compared with attached cells. Accordingly, ROS levels were increased in suspended cells, resulting in the activation of Src and EGFR. NOX4 knockdown decreased activation of Src and EGFR, and thus sensitised cells to anoikis. NOX4 overexpression increased EGFR levels and attenuated anoikis. NOX4 expression is upregulated and is positively correlated with EGFR levels in the lung cancer patient tissues.

Conclusions: NOX4 upregulation confers anoikis resistance by ROS-mediated activation of EGFR and Src, and by maintaining EGFR levels, which is critical for cell survival.

Metastasis is the main cause of tumour mortality. It is a multi-step process that relies on the ability of cancer cells to dissociate from primary sites, survive in the vascular and lymphatic systems, and colonise and proliferate in distant target organs (Kim et al, 2012). Most normal epithelial and endothelial cells adhere to their appropriate extracellular matrix (ECM) through specific integrins, which leads to the activation of cell survival signals. If these cells detach from the ECM or engage with an inappropriate ECM, they undergo anoikis, also known as cell detachment-induced apoptosis (Taddei et al, 2012; Frisch et al, 2013). Anoikis is important for maintaining tissue homeostasis and is essential for preventing the dissemination of cells to inappropriate sites. Normal cells are

\footnotetext{
*Correspondence: Dr Y-K Jung; E-mail: ykjung@snu.ac.kr or Dr Y-N Kim; E-mail: ynk@ncc.re.kr

${ }^{8}$ These authors contributed equally to this work.
}

Received 12 September 2016; revised 3 December 2016; accepted 5 December 2016; published online 12 January 2017

(c) 2017 Cancer Research UK. All rights reserved 0007 - 0920/17 
highly sensitive to anoikis, but some cancer cells acquire anoikis resistance and are able to survive without ECM adhesion in the circulation. Because anoikis provides a critical barrier to the survival of invading cancer cells in the circulatory system, anoikis resistance is an essential prerequisite for tumour metastasis (Kim et al, 2012). Therefore, understanding the cellular and molecular mechanisms that confer anoikis resistance may lead to the identification of novel therapeutic targets to treat and prevent tumour metastasis.

Although the mechanisms of anoikis resistance are not fully understood, studies have demonstrated that reactive oxygen species (ROS) regulate anoikis resistance either positively or negatively, indicating dual effects of ROS depending on cell context (Buchheit et al, 2014; Giannoni and Chiarugi, 2014). It has been reported that growth factor receptors and ROS can mediate the activation of survival signalling pathways, leading to the anoikis resistance of cancer cells (Giannoni and Chiarugi, 2014). Activation of growth factor receptors increases ROS production by activating ROS-generating enzymes such as NADPH oxidase (NOX) and lipoxygenase (Giannoni et al, 2008; Bonner and Arbiser, 2012; Giannoni and Chiarugi, 2014). The NOX family member NADPH oxidase 4 (NOX4) is highly expressed in the kidney and blood vessels, and its physiological and pathological roles have been widely studied in hypertension, atherosclerosis, diabetes, and fibrosis (Bedard and Krause, 2007; Lassegue and Griendling, 2010). Recently, NOX4 has been shown to be associated with several cancers such as glioblastoma, melanoma, and thyroid carcinoma (Yamaura et al, 2009; Weyemi et al, 2010; Hsieh et al, 2011; Shimada et al, 2011; Block and Gorin, 2012; Boudreau et al, 2012; Mondol et al, 2014). In melanoma cells, NOX4 contributes to the transformation phenotype by regulating G2-M cell cycle progression and enhancing cell survival via activation of Akt (Yamaura et al, 2009). Furthermore, in urinary bladder cancer cells, NOX4 inhibition induces cell cycle arrest via p16 induction (Shimada et al, 2011). NOX4 has also been shown to be critical for renal tumourigenesis by promoting the nuclear accumulation of hypoxia-inducible factor $2 \alpha$ (HIF2 $\alpha$ (Gregg et al, 2014).

Elevated ROS levels are frequently observed in tumours where they induce prosurvival signals through the activation of Src and EGFR (Giannoni and Chiarugi, 2014). Activation of the EGFR initiates signalling pathways that promote cell proliferation, migration, and survival, thereby contributing to tumour progression (Tebbutt et al, 2013). Moreover, enhanced activity of EGFR, via overexpression and mutation, is highly associated with several solid tumour malignancies (Tebbutt et al, 2013). Interestingly, EGFR downregulation is associated with anoikis. Upon detachment of a cell from ECM, CCN family protein 2 (CCN2) binds and triggers EGFR degradation, which increases death-associated protein kinase and promotes anoikis (Chang et al, 2013). In addition, ECM detachment upregulates the proapoptotic protein, Bim, which lead to anoikis. However, overexpression of EGFR blocks anoikis by inhibiting Bim expression (Reginato et al, 2003). Furthermore, in breast epithelial cells, the oncogene HER2 stabilises EGFR in ECM-detached cells via activation of the ERK/ Sprouty2 pathway (Grassian et al, 2011). These studies indicate that maintenance of EGFR levels/activity is important for anoikis resistance.

In this study, we demonstrate that detachment of lung cancer cells induces NOX4 expression and increases ROS production, which is critical for the downstream activation of Src and EGFR. We also demonstrate that NOX4 upregulation attenuates EGFR downregulation and maintains EGFR levels and activity during cell detachment, which confers anoikis resistance of lung cancer cells. We further showed that NOX4 expression is upregulated and is positively correlated with EGFR expression in the lung cancer patients.

\section{MATERIALS AND METHODS}

Cell culture. The human lung adenocarcinoma cell line, A549 was purchased from ATCC (American Type Culture Collection). The human bronchial epithelial cell line, BEAS-2B was a kind gift from Yeul Hong Kim (Korea University, Korea). The human lung cancer cell lines, NCI H1703, Calu-6, NCI H460, NCI H358, HCC2279 were from Dr Kyungsil Yoon (National Cancer Center, Korea). BEAS-2B cells were maintained in Keratinocyte-SFM (Invitrogen, Carlsbad, CA, USA) with supplements $(30 \mu \mathrm{g} / \mathrm{ml}$ Bovine Pituitary Extract and $0.2 \mathrm{ng} \mathrm{ml}^{-1} \mathrm{rEGF}$; Invitrogen). A549, NCI H1703, Calu-6, NCI H460, NCI H358, HCC 2279 cells were maintained in RPMI 1640 (Hyclone, Rockford, IL, UAS) supplemented with 10\% fetal bovine serum (Hyclone) and $1 \%$ penicillin and streptomycin (Invitrogen, San Diego, CA, USA) in a $5 \% \mathrm{CO}_{2}$ atmosphere at $37^{\circ} \mathrm{C}$.

Antibodies and reagents. NOX4 antibodies were purchased from Santa Cruz Biotechnology (Santa Cruz, CA, USA), Novus Biologicals (Littleton, CO, USA) and Abcam (Cambridge, UK). NOX2 antibody was purchased from Abcam. Phosphorylated EGFR antibodies (Y845, Y1068, and Y992), Hoechest 33342 and Alexa Fluor 488 goat anti-mouse IgG were purchased from Invitrogen. Anti-EGFR, anti-c-Src, anti-p22 ${ }^{\text {phox }}$, horseradish peroxidase (HRP)-conjugated goat anti-mouse IgG, HRP-conjugated goat anti-rabbit IgG antibodies were obtained from Santa Cruz Biotechnology. Anti-Bim antibody was purchased from Enzo Life Sciences (Farmingdale, NY). anti-Akt, Anti-phospho Akt (S473), anti- ERK1\&2, anti-phospho ERK1\&2 (T202/Y204), anti-phospho Src (Y416), anti-phospho EGFR (Y1068), anti-phospho GSK3 $\beta$ (S9), anti-STAT3, and anti-cleaved caspase-3 were obtained from Cell Signaling Technology (Beverly, MA). Anti-EGFR (528) antibody was purchased from Abcam. Anti- $\beta$-actin antibody, Dimethyl sulfoxide (DMSO), N-acetylcysteine (NAC), Diphenyleneiodonium (DPI), apocynin, plumbagin and Poly (2-hydroxyethyl methacrylate) (Poly-HEMA) were purchased from Sigma (St. Louis, Missouri).

Small interfering RNA preparation and transfection. Validated small interfering RNA (siRNA) duplexes for human NOX4 (SC41586) and human EGFR (SC-29301) were purchased from Santa Cruz Biotechnology (Santa Cruz, CA), and a negative control with a scrambled sequence (SN-1003) was purchased from Bioneer (Daejeon, Korea). A549 cells were reverse transfected with 60 pmol siRNA using Lipofectamine RNAiMAX reagent (Invitrogen) according to the manufacturer's protocol. The A549 cells were trypsinised $24 \mathrm{~h}$ post-transfection and cultured in attached or suspended conditions. The siRNA sequences used to target NOX4 is $5^{\prime}$-AACGAAGGGGUUAAACACCUC- $3^{\prime}$ and EGFR is $5^{\prime}$-CUCUGGAGGAAAAGAAAGU-3'.

Immunoblotting. After washing with ice-cold PBS, cells were lysed with $2 \mathrm{X}$ SDS sample buffer (20 mM Tris ( $\mathrm{pH} 8.0$ ), 2\% SDS, $2 \mathrm{~mm}$ DTT, $1 \mathrm{~mm} \mathrm{Na} \mathrm{VO}_{4}, 2 \mathrm{~mm}$ EDTA, 20\% glycerol) and boiled for $5 \mathrm{~min}$. The protein concentration of each sample was determined using a BCA protein assay reagent (Pierce, Rockford, IL) as described by the manufacturer. In all, $20-50 \mu \mathrm{g}$ of total cellular protein were separated by $8-12 \%$ SDS-PAGE and transferred to PVDF membranes. The membranes were blocked for $1 \mathrm{~h}$ at room temperature in Tris-buffered saline and Tween-20 [TBS-T, $20 \mathrm{~mm}$ Tris (pH 8.0), $150 \mathrm{~mm} \mathrm{NaCl}$ and $0.1 \%$ Tween-20) containing 5\% non-fat dried milk. The membranes were incubated with primary antibody overnight at $4{ }^{\circ} \mathrm{C}$, washed three times with TBS-T, incubated with horseradish peroxidase-conjugated goat anti-mouse IgG or goat anti-rabbit IgG secondary antibodies for $1 \mathrm{~h}$ at room temperature, and then washed three times with TBS-T. The labelled proteins were visualised using the chemiluminescence 
method. The film was scanned, and the protein bands were quantified by densitometric analysis using ImageJ software (http://rsb.info.nih.gov/ij/).

Suspension culture and anoikis assay. Tissue culture plates $(60 \mathrm{~mm})$ were coated with $250 \mu \mathrm{l}$ of poly-HEMA $\left(50 \mathrm{mg} \mathrm{ml}^{-1}\right.$ in $95 \%$ ethanol) and dried overnight in a laminar flow hood at room temperature. Cells were trypsinised into a single cell suspension, and $8 \times 10^{5}$ cells were plated on poly-HEMA-coated dishes. After $24 \mathrm{~h}$, the cells were collected by centrifugation and processed for cell viability, flow cytometric analysis, and protein analysis. For the anoikis assay, collected cells were washed with PBS, cell aggregates were removed with AccuMax (Innovative Cell Technologies, San Diego, CA, USA), and cell survival was determined using trypan blue exclusion. Alternatively, cell viability was analysed using the Live/Dead Viability/Cytotoxicity Kit (Invitrogen) as described in the manufacturer's instructions. Briefly, cells were stained with $0.8 \mu \mathrm{M}$ green-fluorescent Calcein AM and $4 \mu \mathrm{M}$ redfluorescent ethidium homodimer-1 for $30 \mathrm{~min}$ at room temperature. The labelled cells (green $=$ live cells, red $=$ dead cells) were analysed using an Axio Observer Z1 fluorescence microscope (Carl Zeiss Microimaging, Thornwood, NY, USA) and an Axion Vision camera (Axion Technologies, Houston, TX, USA).

Production of NOX4-expressing lentivirus. The NOX4/pCMVSPORT6 vector was obtained from 21C Frontier Human Gene Bank (KRIBB, Daejeon, Korea). Lentivirus was produced using the Viralpower Lentiviral Expression System (Invitrogen). Briefly, the NOX4 open reading frame (ORF) was amplified from the NOX4/ pCMV-SPORT6 vector using the following primers: forward (5'-CCCGGGACCATGGCTGTGTCC- $3^{\prime}$ ) and reverse (5'-GCGG CCGCTCAGCTGAAAGACTC- $3^{\prime}$ ). The NOX4 cDNA was subcloned into the pLenti6/V5-D-TOPO vector according to the manufacturer's protocol. The resultant NOX4/pLenti6-D-TOPO vector was verified using PCR, restriction digestion, and sequence analysis (Macrogen, Seoul, Korea). The pLenti6/V5-GW/lacZ (Invitrogen) vector was used as a positive control. Recombinant lentiviruses were produced according to the manufacturer's protocol (Invitrogen). Briefly, we co-transfected the pLenti6/V5D-TOPO (NOX4 or LacZ) vector and the Lentiviral Packaging Mix (Invitrogen) into 293 FT cells. After 48 h, the viral supernatant was collected, spun to remove cell debris, filtered through a Millex-HV syringe filter $(0.45 \mu \mathrm{m}$, Millipore, Bedford, MA, USA), and stored at $-80{ }^{\circ} \mathrm{C}$.

NOX4 overexpression in A549 cells. A549 cells were infected with the lentiviral supernatants and $2 \mu \mathrm{g} \mathrm{ml}^{-1}$ polybrene (hexadimethrine bromide). After $24 \mathrm{~h}$, the medium was changed, and then the cells were incubated for $48 \mathrm{~h}$ prior to selection in $10 \mu \mathrm{g} \mathrm{ml}^{-1}$ blasticidin-containing media for 14 days to generate stable cell lines. The expression of respective proteins was verified via immunoblot analysis.

Microarray analysis. Microarray experiments were performed using tools from the commercial microarray service Ebiogen, Inc. (Seoul, Korea). Total RNA was isolated from A549 cells grown in attachment or suspension conditions using Trizol reagent (Invitrogen) according to the manufacturer's instructions. The isolated RNA was amplified and subjected to cDNA microarray (Ebiogen). Briefly, amplified cRNA was hybridised to Agilent's Human Oligo Microarray (44 K) (Agilent Technology, Palo Alto, CA, USA). The hybridised images were scanned using Agilent's DNA microarray scanner and quantified with Feature Extraction Software (Agilent Technology). The data normalisation and selection of fold-changed genes were performed using GeneSpring GX 7.3 (Agilent Technology). The averages of normalised ratios were calculated by dividing the average of normalised signal channel intensity by the average of normalised control channel intensity. The functional annotation of genes was performed according to Gene
Ontology Consortium (http://www.geneontology.org/index.shtml) by GeneSpringGX 7.3. The gene classification was based on searches done by BioCarta (http://www.biocarta.com), GenMAPP (http:// www.genmapp.org), DAVID (http://david.abcc.ncifcrf.gov) and Medline databases (http://www.ncbi.nlm.nih.gov).

Reverse transcription-polymerase chain reaction (RT-PCR). After total RNA extraction, single-stranded cDNA was generated using Maxime RT PreMix (Oligo $\mathrm{dT}_{15}$ Primer; iNtRON Biotechnology, Kyungki-Do, Korea) following the manufacturer's directions. Synthesised cDNA fragments were amplified with the following primer pairs: $A C T B, 5^{\prime}$-ACAACGGCTCCGGCATGTGCAA-3' (sense) and 5'-CGGTTGGCCTTGGGGTTCAG-3' (antisense); GAPDH, $5^{\prime}$-CTTTGGTATCGTGGAAGGA- $3^{\prime}$ (sense) and 5'-CACCCTGTTGCTGTAGCC-3' (anti-sense); NOX4, 5' -AGGAGAACCAGGAGATTGTTG- $3^{\prime}$ (sense) and $5^{\prime}$-GGGATGACTT ATGACCGAAAT- $3^{\prime}$ (anti-sense); p22 phox, $5^{\prime}$-GTGTTTGTGTG CCTGCTGGAGT-3' (sense) and $5^{\prime}$-CTGGGCGGCTGCTTGATG GT-3' (anti-sense); EGFR, 5'-GCAAATAAACCGGACTGAAG-3' (sense) and $5^{\prime}$-GTGGCACCAAAGCTGTATTTG-3' (anti-sense); NOX2, 5'-GGGCTGTTCAATGCTTGTGGCT-3' (sense) and 5'-A CATCTTTCTCCTCATCATGGTGC-3' (anti-sense); NOX5, $5^{\prime}$-A TCAAGCGGCCCCCTTTTTTTCAC-3' (sense) and $5^{\prime}$-CTCAT TGTCACACTCCTCGACAGC-3' (anti-sense). PCR was performed using a T-Gradient Thermal Cycler (Biometra, Goettingen, Germany) and AccuPower PCR Premix (Bioneer) according to the manufacturer's protocol. $A C T B$ and GAPDH were used as the housekeeping genes. The PCR products were resolved on $1.5 \%$ agarose gels and visualised using a BioDoc-it Imaging System (UVP, Upland, CA, USA).

Flow cytometry analysis. For ROS measurements, A549 cells grown in attachment or suspension conditions were incubated with $20 \mu \mathrm{M}$ of $\mathrm{CM}-\mathrm{H}_{2} \mathrm{DCFDA}$ for $40 \mathrm{~min}$ at $37^{\circ} \mathrm{C}$, collected, and analysed by flow cytometry using a FACSCalibur (Becton Dickinson Bioscience, San Jose, CA, USA). To quantify EGFR surface expression levels, cells were trypsinised and suspended in PBS containing $1 \%$ FBS. Approximately $5 \times 10^{5}$ cells were stained for $30 \mathrm{~min}$ with either monoclonal anti-EGF receptor antibody (mAb 528) or IgG isotype control. The cells were then washed with ice-cold PBS and incubated for $30 \mathrm{~min}$ with Alexa 488-conjugated secondary IgG anti-mouse $\left(1 \mu \mathrm{g}\right.$ of antibody $/ 2 \times 10^{5}$ cells in $\left.100 \mu \mathrm{l}\right)$ for $30 \mathrm{~min}$. The cells were subsequently washed with ice-cold PBS and analysed using FACSCalibur. All antibody incubations and washing steps were carried out at $4{ }^{\circ} \mathrm{C}$. The raw data were analysed by Cell Quest Software (BD Bioscience) at the flow cytometry core facility of the National Cancer Center (Gyeonggi-do, Korea).

Immunofluorescence and confocal microscopy imaging. Cells grown on cover slips were fixed with $3.7 \%$ paraformaldehyde in PBS on ice for $20 \mathrm{~min}$, and then rinsed with PBS. The fixed cells were treated with $1.5 \mathrm{mg} \mathrm{ml}^{-1}$ glycine in PBS to quench the free aldehyde groups, blocked with $3 \%$ BSA in PBS for $1 \mathrm{~h}$ at room temperature, and rinsed with PBS. The cells were stained with antiEGFR antibodies (mAb 528) or non-specific IgG overnight at $4{ }^{\circ} \mathrm{C}$, washed with PBS, and then exposed to Alexa 488-conjugated secondary IgG for $1 \mathrm{~h}$ at room temperature. For nuclear staining, the cells were incubated with Hoechst 33342 in PBS for 5 min at room temperature. The cover slips were washed in PBS and mounted on glass slides. Immunofluorescence was measured on a Zeiss LSM 510 laser scanning microscope (Carl Zeiss, Jena, Germany).

Soft agar assay. A549 cells were transfected with si-control, siNOX4, or si-EGFR for $24 \mathrm{~h}$ and soft agar assays were performed in $35 \mathrm{~mm}$ plates by placing $1 \times 10^{3}$ cells in $1 \mathrm{ml}$ of $0.3 \%$ agar onto a base layer $1 \mathrm{ml}$ of $0.8 \%$ agar. The plates were then covered with $1 \mathrm{ml}$ of fresh RPMI medium containing 10\% FBS and incubated in a $5 \% \mathrm{CO}_{2}$ atmosphere at $37^{\circ} \mathrm{C}$ for 2 weeks. Cell growth medium 
was changed every third day. Colonies were stained with iodonitro tetrazolium violet (INT) solution (Sigma, $0.5 \mathrm{mg} \mathrm{ml}^{-1}$ ) and images were taken by Kodak Image Station 2000R (Eastman Kodak Company, New Haven, CT, USA).

Immunohistochemical staining for lung cancer tissue microarray. Tissue arrays were obtained from Superbiochips Laboratories (Seoul, Korea) that has been described previously (Sung et al, 2014). Each array contained 60 sections of $4 \mu \mathrm{m}$ thickness obtained from 60 patients by biopsy or surgical resection. The primary antibodies used were polyclonal rabbit anti-NOX4 (1:100 dilutions; Novus Biologicals) and polyclonal rabbit anti-EGFR antibody (1:100 dilutions; Santa Cruz Biotechnology). The tumour tissues incubated with primary antibodies for $1 \mathrm{~h}$ were then treated with anti-rabbit biotinylated antibody (1:1000 dilutions; Vector Laboratories) for $1 \mathrm{~h}$. Colour reaction was developed by incubation with diaminobenzidine solution (Sigma) followed by counter staining with hematoxylin. Parallel sections incubated with normal IgG instead of primary antibodies were used as negative controls. The overall staining results were scored from 0 to 3 based on the intensity and positive rate of staining. Intensity of staining was categorised as 0 , negative $(-) ; 1$, weak $(+) ; 2$, intermediate $(++)$; 3 , strong $(+++)$. Stained tissue arrays were reviewed by two experienced pathologists.

Statistical analysis. All data points represent average values and s.d. (error bars) obtained from three independent experiments performed in triplicate. Comparison between two groups was performed using Student's $t$-test. Statistical significance was defined as a $P$-value $<0.05$. The relationship between NOX4 expression and clinocopathologic characteristics were analysed by Pearson's $\chi^{2}$ method.

\section{RESULTS}

Anoikis resistance in A549 human lung epithelial adenocarcinoma cells. Normal epithelial cells are known to be sensitive to anoikis, whereas cancer cells often acquire anoikis resistance (Kim et al, 2012). To compare anoikis sensitivity, we employed immortalised normal bronchial epithelial cells (BEAS-2B) and lung carcinoma cells (A549). When cultured in suspension, A549 cells formed larger cell aggregates at a more rapid rate than BEAS-2B cells and overall aggregate sise for the A549 cells was larger than that of BEAS-2B cells (Figure 1A). Cells in suspension that form mutlicellular aggregates are known to be more anoikis-resistant than single cells (Zhang et al, 2004). During suspension culture, A549 cell number increased, although the growth rate was very slow, whereas BEAS-2B cell number decreased (Figure 1B). In addition, caspase 3 activation determined by caspase 3 cleavage was enhanced in suspended BEAS-2B cells when compared with A549, suggesting that BEAS-2B cells are more sensitive to anoikis, than A549 cells (Figure 1C). Next, we examined changes in several signalling molecules that are important for cell survival. Although total levels of EGFR decreased in A549 cells grown in suspension, the level of phosphorylation of EGFR at multiple tyrosine residues including Y845 and Y1068 increased (Figure 1D and Supplementary Figure 1). In addition, A549 cells grown in suspension showed increased levels of activated Src and ERK1\&2, as determined by their phosphorylation (Figure 1D), whereas Akt phosphorylation remained unchanged. However, we did not detect activation of these molecules in the normal BEAS-2B cells (Figure 1D), indicating that they are selectively activated in cancer cells to mediate anoikis resistance.

NOX4 upregulation and ROS generation in anoikis resistant A549 cells. To examine differential gene expression that is dependent on cell adhesion, we performed mRNA expression arrays using RNA from A549 cells grown in suspension and adherent culture conditions. NADPH oxidase 4 (NOX4) showed a threefold increase in suspended cells compared with attached cells (Figure 2A). We validated NOX4 upregulation at the mRNA and protein levels in suspended cells by RT-PCR and immunoblotting, respectively (Figure 2B). Interestingly, p22 ${ }^{\text {phox }}$, a functional partner of NOX4 (Bedard and Krause, 2007; Lassegue and Griendling, 2010), was also increased from $4 \mathrm{~h}$ and remained increased at the mRNA and protein levels upon cell detachment (Figure 2C). However, NOX2 and NOX5, other members of the NOX family, showed little change in their expression levels (Figure 2D).

Because we observed NOX4 and $\mathrm{p} 22^{\text {phox }}$ upregulation in cells grown in suspension, we investigated differences between ROS generated from cells that were grown in suspended and attached conditions. Flow cytometry analysis of $\mathrm{CM}-\mathrm{H}_{2} \mathrm{DCFDA}$, a ROSsensitive dye, revealed an increase in ROS levels in the suspended cells that was decreased by treatment with the ROS scavenger NAC and the NOX inhibitor diphenyleneiodonium (DPI) (Figure 3A). Cell viability was also decreased by treatment with the NOX inhibitors DPI and apocynin (Figure 3B). In addition, NOX inhibition in the suspension culture resulted in decreased activation of EGFR and Src (Figure 3C). However, NOX inhibitor, DPI did not affect EGFR phosphorylation in the attached A549 cells (Supplementary Figure 2). More specifically, administration of plumbagin, which has been shown to inhibit NOX4 (Ding et al, 2005), to cells grown in suspension, decreased cell aggregation and reduced ROS generation (Figure $3 \mathrm{D}$ and $\mathrm{E}$ ). Consistent with the results using NOX inhibitors (Figure 3B), plumbagin treatment induced the death of suspended cells (Figure 3F), indicating that plumbagin sensitises cells to anoikis. Plumbagin treatment also decreased EGFR activation and this inhibition appeared to be selective because plumbagin had little effect on other pathways, including Akt activation (Figure 3G). These data indicate that cell detachment increases ROS production, probably through induction of NOX4 expression, and that increased ROS levels are critical for anoikis resistance.

To further investigate NOX4 involvement in anoikis resistance, we overexpressed NOX4 (Figure 4A) or depleted NOX4 using siRNA (Figure 4B). NOX4 overexpression did not affect the growth of attached cells. However, knockdown of NOX4 attenuated the growth of attached cells regardless of NOX4 overexpression (Figure 4C). In suspension culture, NOX4 overexpression caused a slight increase in cell aggregation, whereas NOX4 depletion caused a notable inhibition in cell aggregation that was attenuated in the NOX4-overexpressing cells (Figure 4C). NOX4 knockdown also induced cell death (Figure 4D) and increased caspase-3 activation (Figure 4E) in suspension culture condition. Accordingly, cell growth also decreased in NOX4-depleted cells compared with control cells (Figure 4F). These data indicate that increased NOX4 expression is essential for the anoikis resistance of suspended A549 cells.

NOX4 expression increases EGF receptor levels. Because NOX4 knockdown sensitised suspended cells to anoikis, and because EGFR is a well-known regulator of cell survival and anoikis resistance (Reginato et al, 2003), we tested whether NOX4 affects EGFR levels or activation. Interestingly, knockdown of NOX4 downregulated EGFR levels in both attached and detached cells (Figure 5A). In addition, the majority of EGFR was localised to the plasma membrane in the control cells, but its localisation shifted from the plasma membrane to the cytoplasm in the NOX4knockdown cells (Figure 5B). Consistent with this observation, flow cytometry analysis demonstrated that cell surface levels of EGFR decreased in the NOX4-knockdown cells compared with control cells (Figure 5C). To further investigate the association of NOX4 with EGFR levels, we examined EGFR levels in the NOX4 overexpressing. EGFR levels were upregulated in the 
A
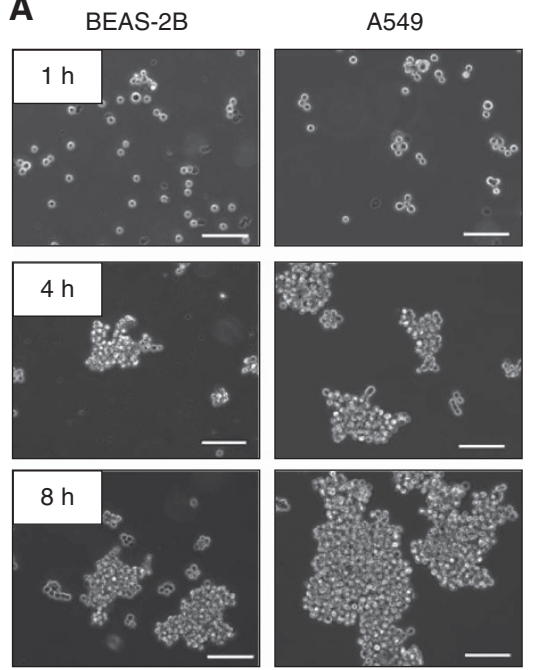

D

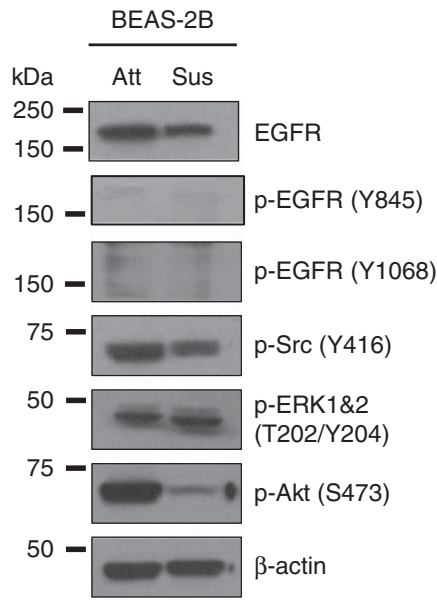

B
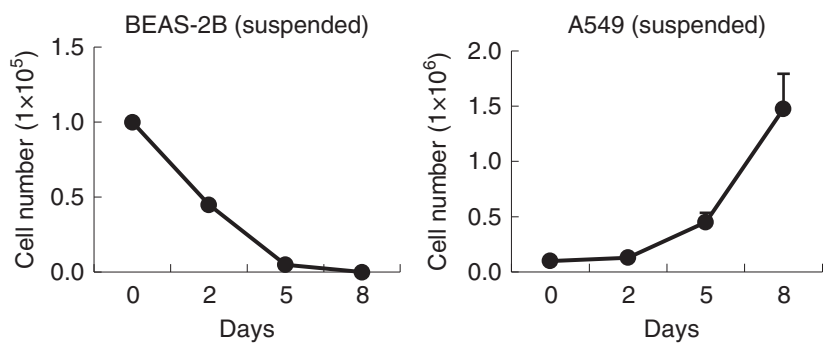

C
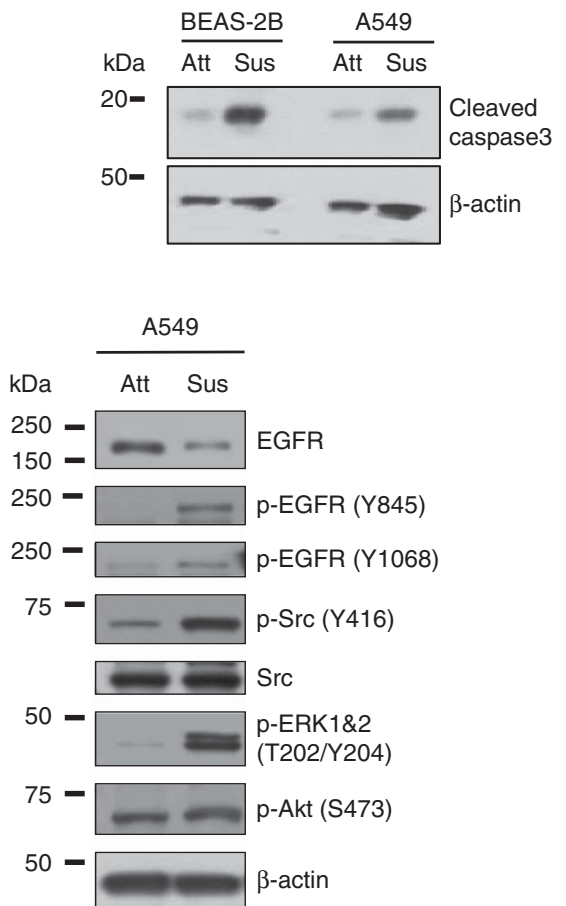

Figure 1. Cell aggregate formation and anoikis resistance in BEAS-2B normal lung epithelial cells and A459 lung cancer cells. (A and B) BEAS-2B and A549 cells were cultured in suspension and cell images were captured with a Zeiss inverted microscope at indicated times (A), cell numbers were counted by Tryphan blue exclusion assay on indicated days (B), and BEAS-2B and A549 cells in suspended for $24 \mathrm{~h}$ were analysed of apoptosis with immunoblot of cleaved caspase 3 (C and D). Equal aliquots of protein $(20 \mu \mathrm{g})$ from cells grown in attachment or suspension conditions were processed for immunoblot analysis using the indicated antibodies. $\beta$-actin was used as a loading control. The data are presented as averages of triplicate measurements with the error bars representing s.d. Scale bar: $100 \mu \mathrm{m}$. The experiments were performed three times with similar results.

NOX4-overexpressing cells compared with mock cells in both attached and detached cells (Figure 5D). In addition, although EGFR levels decreased upon NOX4 knockdown in NOX4-overexpressing and control cells, this decrease was attenuated in NOX4-overexpressing cells. However, NOX4 knockdown did not reduce STAT3 total levels, suggesting that NOX4 knockdown downregulates EGFR selectively (Figure 5E). EGFR overexpression is known to inhibit anoikis by downregulation of a pro-apoptotic protein, Bim (Reginato et al, 2003). Because NOX4 expression positively regulates EGFR levels, we tested whether NOX4 expression decreases Bim exppression. Bim protein levels decreased when NOX4 was overexpressed, whereas they increased when NOX4 was knockdowned (Figure 5F and $5 \mathrm{G}$ ). Furthermore, knockdown of another NOX family member, NOX2, did not decrease EGFR protein levels or its phosphorylation, whereas NOX4 knockdown decreased both (Figure 5H). Consistent with these data, NOX4 knockdown induced anoikis sensitisation, whereas NOX2 knockdown had little effect on anoikis (Figure 5I). Taken together, these data indicate that NOX4 selectively upregulates EGFR protein levels and thus maintains EGFR activity, which likely contributes to anoikis resistance.
EGFR downregulation upon cell detachment. Interestingly, our microarray data revealed that EGFR expression decreased in suspension-cultured cells (Figure 6A). Consistent with these data, the mRNA and protein levels of EGFR decreased in a timedependent manner upon cell detachment (Figure 6B and C). However, the phosphorylation of EGFR at Tyr 992 and Tyr 1068 remained elevated compared with those of attached cells (Figure 6C). To determine the role of EGFR in anoikis resistance, we depleted EGFR using siRNA in A549 cells. In attached cells, EGFR knockdown inhibited cell growth but did not induce cell death. However, in suspended cells, EGFR knockdown not only reduced cell aggregate formation but also induced cell death (Figure 6D). In addition, EGFR knockdown resulted in Src inactivation in the suspended cells (Figure 6E). Furthermore, EGFR or NOX4 knockdown inhibited the colony forming ability of A549 cells under anchorage-independent growth conditions (Figure 6F). Interestingly, EGFR and NOX4 were upregulated in several lung cancer cell lines, including A549, H1703, Calu-6, H460, H358, and HCC2279 cells, compared with BEAS-2B normal bronchial epithelial cells (Figure 6G). These data indicate that 
A

\begin{tabular}{|c|c|c|c|c|c|}
\hline $\begin{array}{c}\text { Sus per Att } \\
\text { ratio }\end{array}$ & Raw & Control & Genbank & $\begin{array}{c}\text { Gene } \\
\text { symbol }\end{array}$ & Description \\
\hline 3.1 & 31 & 10 & NM_016931 & NOX4 & NADPH oxidase 4 \\
\hline
\end{tabular}

B
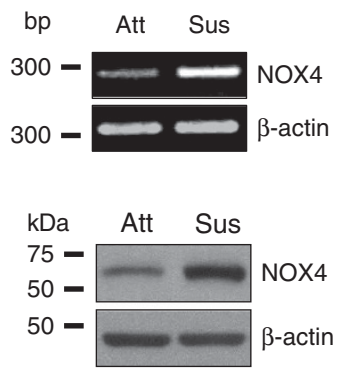

C
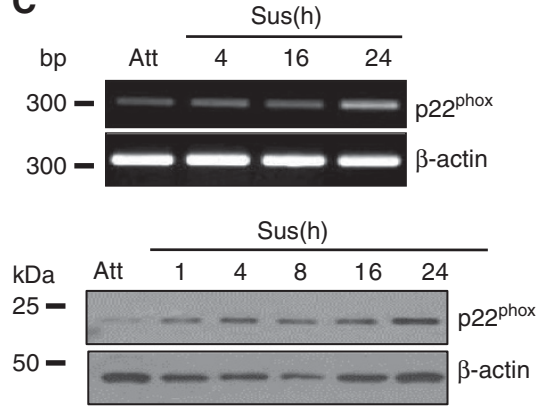

D

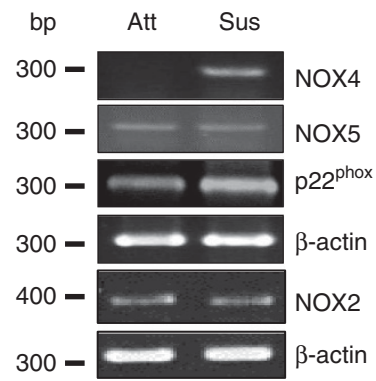

Figure 2. Upregulation of NOX4 and its functional partner p22 $2^{\text {phox }}$ in A459 cells in suspension culture. (A) A549 cells were grown in attached or suspended conditions for $24 \mathrm{~h}$ and total RNA was extracted and processed for microarray analysis as described in the 'Materials and Methods'. (B-D) A549 cells were grown in attached or suspended conditions for indicated times followed by total mRNA extraction and cell lysate preparation. The expression levels of NOX4, p22 $2^{\text {phox }}$, NOX5, and NOX2 were determined by RT-PCR or by immunoblotting using the indicated antibodies. The experiments were performed three times with similar results.

maintenance of certain levels of EGFR is critical for cell survival when cells are ECM-detached.

NOX4 upregulation is positively correlated with lung cancer. To explore clinical significance of NOX4 expression in the lung cancer patients, we examined NOX4 expression in a lung cancer tissue microarray from 96 patients using anti-NOX4 antibodies or anti-EGFR antibodies. As shown in Figure $6 \mathrm{H}$, there was little NOX4 expression in the adjacent normal tissues, whereas NOX4 expression was upregulated in the lung cancer tissues. Immunohistochemical analyses showed that NOX4 expression was overall enhanced from the early stage of cancer in about $83 \%(80 / 96)$ of the lung cancer patient tissues (Table 1). Out of 96 samples, 9 primary tumour samples were obtained from metastatic patients and all of 9 samples showed very strong staining for NOX4. Interestingly, NOX4 expression appeared to be correlated with EGFR expression. For example, NOX4 expression was increased in 96\% (43/45) of EGFR-positive lung cancer patients (Table 2). All these data indicate that NOX4 expression is upregulated in the lung cancer patients and its expression is positively correlated with EGFR expression levels.

\section{DISCUSSION}

Upon cell detachment, integrin-mediated cell survival signals are downregulated and apoptosis signals are activated, leading to cell death. This process, known as anoikis, is essential during normal development to get rid of unwanted or mislocalised cells (Frisch et al, 2013; Paoli et al, 2013). However, cancer cells acquire anoikis resistance to allow for their circulation in the blood or lymphatic system, which is essential for successful cancer metastasis (Kim et al, 2012). Therefore, understanding mechanisms of anoikis resistance could lead to the discovery of therapeutic targets to control or prevent cancer metastasis. In this regard, our present study demonstrated that NOX4 upregulation upon cancer cell detachment was critical for anoikis resistance. We illustrated that NOX4 upregulation resulted in the activation of Src and EGFR, which enhanced cell survival in suspension culture. We also showed that NOX4 overexpression attenuated EGFR downregulation, thereby maintaining levels of EGFR upon cell detachment, and that NOX4 expression was positively correlated with EGFR levels in lung cancer patients. To our knowledge, these data provide the first evidence that NOX4 expression regulates anoikis resistance via activation of Src and EGFR and upregulation of EGFR levels.

NADPH oxidases of the NOX family are ROS-generating enzymes that regulate redox-dependent signalling pathways associated with cancer development and progression (Block and Gorin, 2012). NOXs transfer electrons across the cell membrane from NADPH to oxygen, generating superoxide anions, which are then dismutated to form $\mathrm{H}_{2} \mathrm{O}_{2}$. Among NOX family members, NOX4 is unique in that it requires relatively few accessory proteins and preferentially produces $\mathrm{H}_{2} \mathrm{O}_{2}$ rather than superoxide anions (Block and Gorin, 2012). $\mathrm{H}_{2} \mathrm{O}_{2}$ is known to activates NOX4derived ROS signalling participates in tumour progression via inhibiting apoptosis, inducing EMT, and promoting cell invasion (Vaquero et al, 2004; Shimada et al, 2011; Boudreau et al, 2012; Hsieh et al, 2012; Hiraga et al, 2013; Bauer et al, 2014; Gregg et al, 2014; Mondol et al, 2014). Because NOX4 is constitutively active, it is thought to be regulated primarily at the gene expression level (Block and Gorin, 2012). In addition, it has been reported that $\mathrm{p} 22^{\text {phox }}$ upregulation by IGF-1 increases NOX4 activity (Edderkaoui et al, 2011). In our study, we found that culturing A549 cells in suspension led to elevated expression of NOX4 and its partner $p 22^{\text {phox }}$ in a time-dependent manner (Figure 2). Accordingly, upon cell detachment, $\mathrm{H}_{2} \mathrm{O}_{2}$ levels increased and Src activity was elevated. Conversely, treatment with NOX inhibitors, including DPI and apocynin, and siRNA-mediated NOX4 knockdown decreased Src activation and sensitised cells to anoikis. Treatment with plumbagin, a NOX4 inhibitor (Ding et al, 2005), also sensitised cells to anoikis and decreased ROS levels (Figure 3). These data indicate that NOX4 upregulation and Src activation are critical for anoikis resistance. To test whether NOX4 upregulation in suspension culture is restricted to the A549 cell line, we employed several lung cancer cell lines, including H1975, H1703 and Calu-6. We found that all three cell lines exhibited cell aggregate formation with little anoikis and NOX4 upregulation in suspension culture (Supplementary Figure 4), indicating that NOX4 upregulation is not limited to A549 cells. In PC3 cells, ROS production by 5-lipoxygenase (5-LOX) induces Src activation upon cell detachment, which is important for anoikis resistance 
A
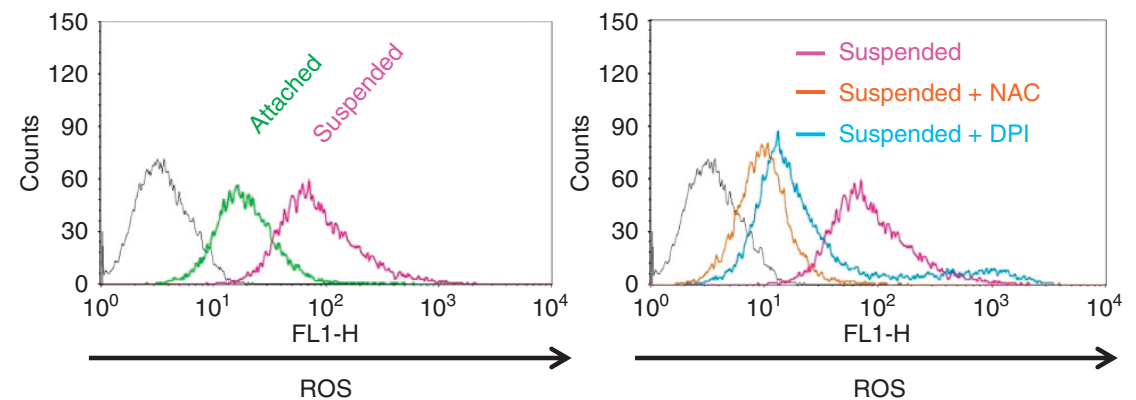

B

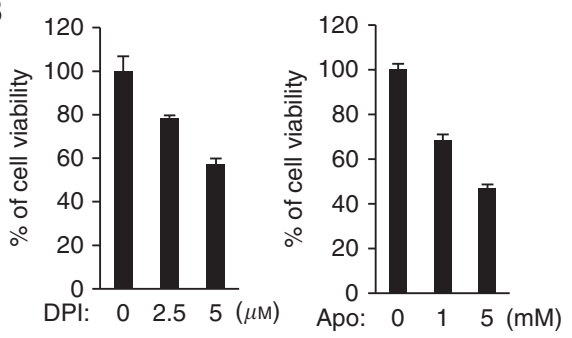

C

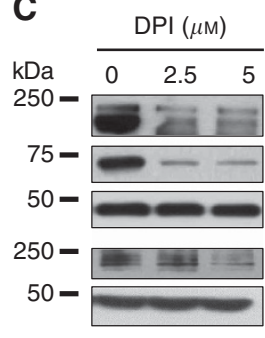

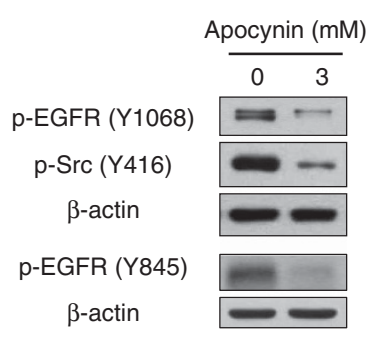

D

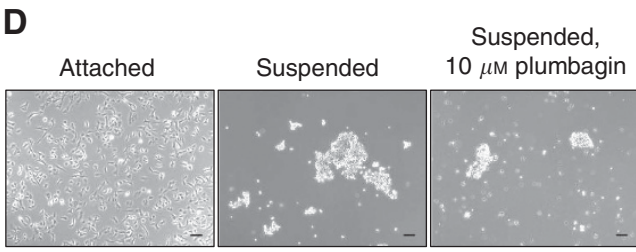

E
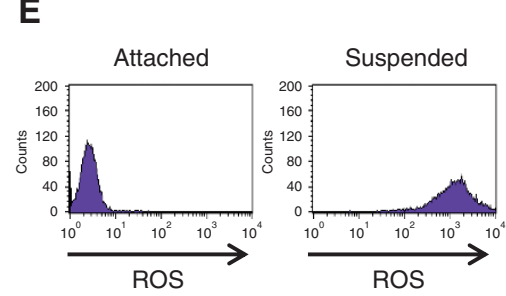

Suspended,

$10 \mu \mathrm{m}$ plumbagin

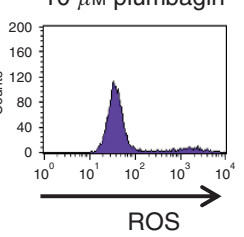

$\mathbf{F}$

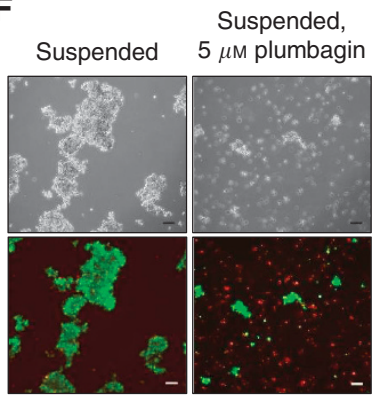

G
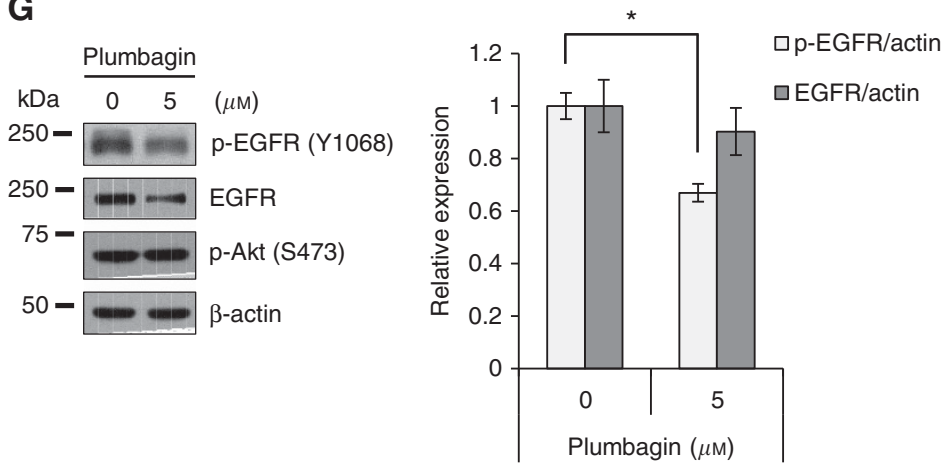

Figure 3. Association of ROS generation with anoikis resistance in suspended A549 cells. (A) A549 cells were grown in attached or suspended conditions for $24 \mathrm{~h}$. For inhibitor treatments, A549 cells grown in suspension were treated with either $30 \mu \mathrm{m}$ of NAC, a ROS scavenger, or $5 \mu \mathrm{m}$ of DPI, a pan-NOX inhibitor. The ROS levels were measured by flow cytometry using a ROS-sensitive dye, CM- ${ }_{2}$ DCFDA. (B) A549 cells grown in suspension were treated with the NOX inhibitors DPI or apocynin or $24 \mathrm{~h}$, and cell viability was measured using an MTS assay. (C) Total cell lysates from A549 cells treated as in B were subjected to immunoblotting analysis using the indicated antibodies. (D-G) A549 cells grown in suspension were treated with plumbagin for $24 \mathrm{~h}$ prior to capturing images of the cell aggregates with a Zeiss inverted microscope (D), measuring ROS levels by flow cytometry (E), analyzing the levels of cell death by staining with green-fluorescent Calcein AM and red-fluorescent ethidium homodimer-1 (green = live cells; red = dead cells) (F), and performing immunoblotting analysis using indicated antibodies (G). The ratio of EGFR or phosphorylated EGFR to actin in the control cells was set at 1. Scale bar: $100 \mu \mathrm{m}$. The data are presented as averages of triplicate measurements with the error bars representing standard deviations $\left({ }^{\star} P<0.05\right)$. These experiments were performed three independent times with comparable results.

(Giannoni et al, 2009). In our study, treatment with the NOX inhibitor DPI sensitised cells to anoikis; however, treatment with the 5-LOX inhibitor nordihydroguaiaretic acid showed little effect on anoikis sensitivity (data not shown), indicating that NOX4 plays the major role in promoting anoikis resistance in A549 cells.

Intriguingly, we found that NOX4 expression was associated not only with EGFR phosphorylation levels but also with its protein expression levels (Figure 5). It is likely that NOX4 upregulation augments EGFR phosphorylation via $\mathrm{H}_{2} \mathrm{O}_{2}$ because NOX4 preferentially produces $\mathrm{H}_{2} \mathrm{O}_{2}$ rather than superoxide anions (Block and Gorin, 2012). NOX4 inhibitor, DPI, decreased both ROS generation and EGFR activation (Figure 3A-C). Another NOX4 inhibitor, plumbagin, also decreased ROS levels and EGFR phosphorylation (Figure $3 \mathrm{E}$ and $\mathrm{G}$ ). $\mathrm{H}_{2} \mathrm{O}_{2}$ is an important mediator for EGFR phosphorylation induced by various stimuli, including ultraviolet radiation (Peus et al, 1998). We observed that 
A

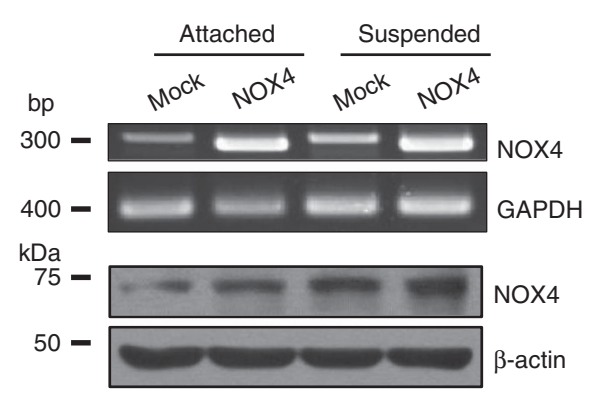

C
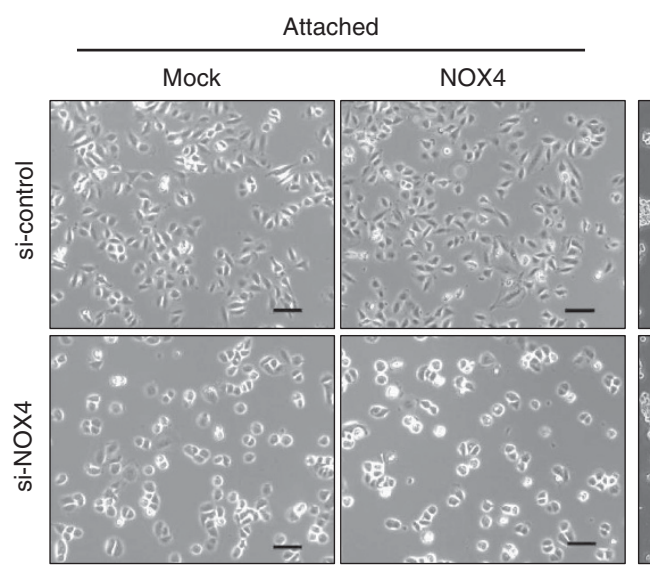

B
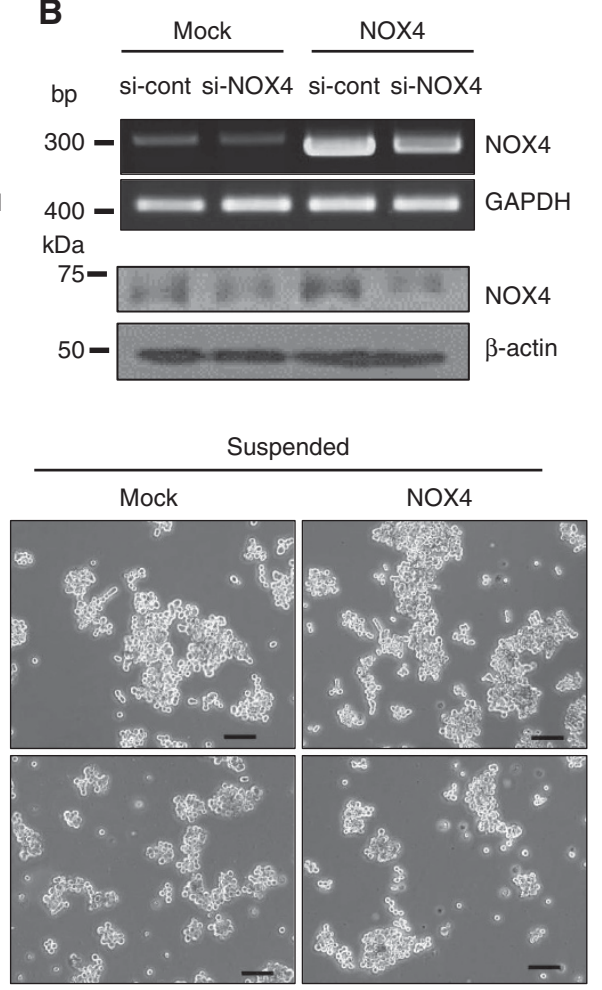

D

si-control
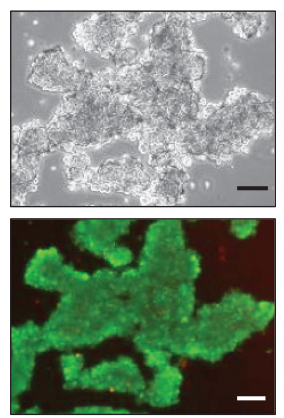

si-NOX4

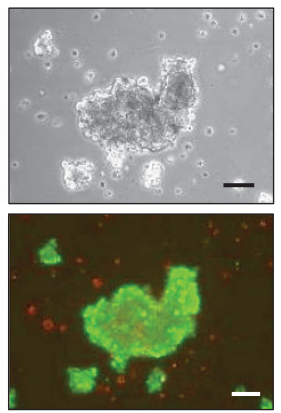

E

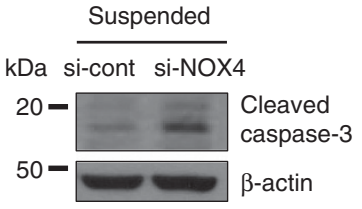

$\mathbf{F}$

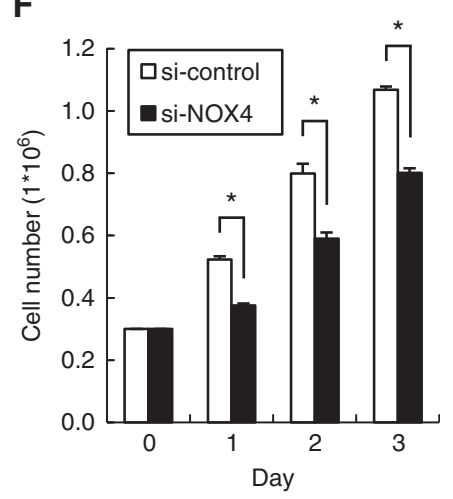

Figure 4. Effect of NOX4 levels on viability and growth of A549 cells grown in suspension. (A) Mock or NOX4-overexpressing A549 cells were grown in attached or suspended conditions for $24 \mathrm{~h}$. NOX4 mRNA levels were determined by RT-PCR using GAPDH as a loading control. Nox4 protein levels were determined by immunoblotting using the indicated antibodies. (B) Mock or NOX4-overexpressing A549 cells were transfected with non-specific siRNA (si-control) or with siRNA specific for NOX4 (si-NOX4) for $24 \mathrm{~h}$, and the levels of NOX4 mRNA were determined by RT-PCR. Nox4 protein levels were determined by immunoblotting using the indicated antibodies. (C) Mock or NOX4-overexpressing A549 cells were transfected with si-control or si-NOX4 and were grown in attached or suspended conditions for $24 \mathrm{~h}$. The cells were imaged using a Zeiss inverted microscope. (D-F) A549 cells were transfected with si-control or si-NOX4 and were grown in suspended conditions for $24 \mathrm{~h}$. The cells were subjected to viability analysis (D), immunoblotting analysis (E), and cell counting at the indicated times (F). Scale bar: $100 \mu \mathrm{m}$. The data are presented as averages of triplicate measurements with the error bars representing standard deviations $\left.{ }^{\star} P<0.05\right)$. Similar results were observed in three independent experiments.

exogenous $\mathrm{H}_{2} \mathrm{O}_{2}$ treatment of A549 cells resulted in EGFR phosphorylation (Supplementary Figure 5). Next, we tested whether NOX2 and NOX4 have a different capacity to generate ROS, and thus affect cell aggregates formation differently. NOX4 knockdown decreased cell aggregate formation within $4 \mathrm{hr}$ in suspended cells whereas NOX2 knockdown affected little (Supplementary Figure 6A). Both si-NOX2 and si-NOX4 could reduce ROS levels compared with si-cont but the degree of ROS inhibition was higher in the si-NOX4 cells than in the si-NOX2 (Supplementary Figure 6B and 6C). These results correlate with the data in Figure 5 showing that si-NOX4, but not si-NOX2, inhibits EGFR phosphorylation. Therefore, it is possible that $\mathrm{H}_{2} \mathrm{O}_{2}$ induced by NOX4 is responsible for EGFR activation in the suspended cells. Maintenance of EGFR expression levels is important for anoikis resistance (Reginato et al, 2003; Giannoni et al, 2009; Lee et al, 2009). ECM detachment induces a dramatic decrease in EGFR levels, which is responsible for anoikis, and overexpression of EGFR blocks anoikis in MCF-10A human mammary epithelial cells (Reginato et al, 2003). In addition, overexpression of ErbB2 increases Sprouty2 protein levels, which inhibits Cbl-induced degradation of EGFR, thereby maintaining EGFR levels (Grassian et al, 2011). In our study, NOX4 knockdown induced anoikis and decreased EGFR levels, whereas NOX4 overexpression attenuated anoikis and EGFR downregulation, suggesting that NOX4 
A si-RNA: cont NOX4 4 cont NOX4 kDa 250- - - EGFR $50--\infty-\infty$-actin $75-\square$ NOX4 $50-\Longrightarrow \beta$-actin

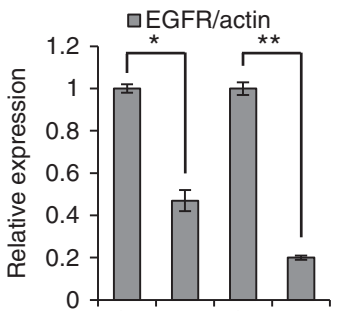

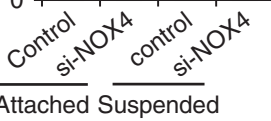

D

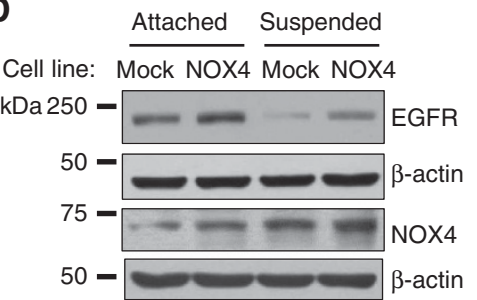

$\mathbf{F}$

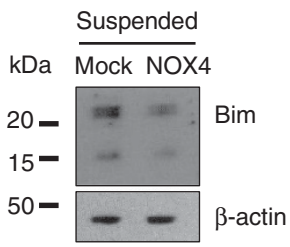

G

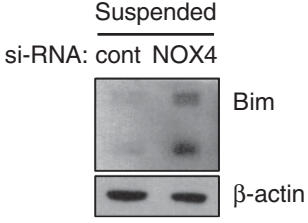

I

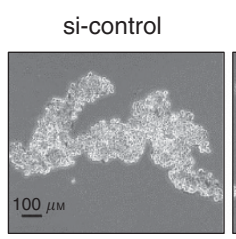

B

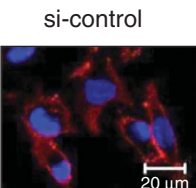

EGFR DAPI

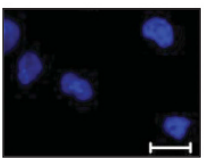

IgG DAPI
si-NOX4

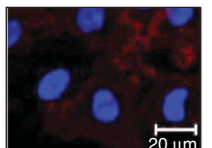

EGFR DAPI

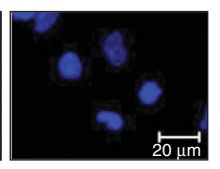

IgG DAPI
C

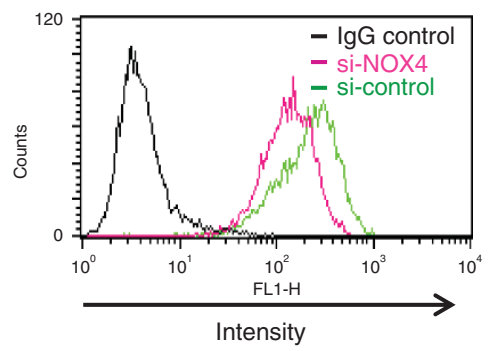

E

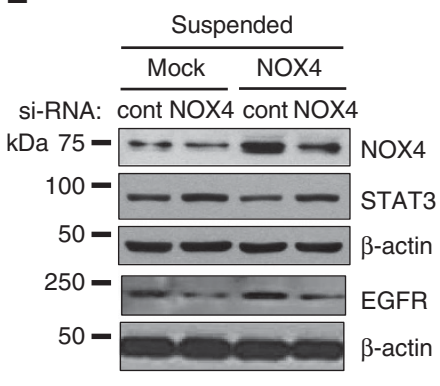

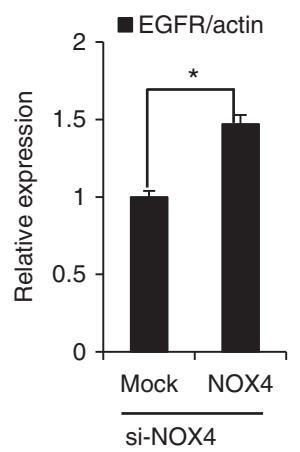

H

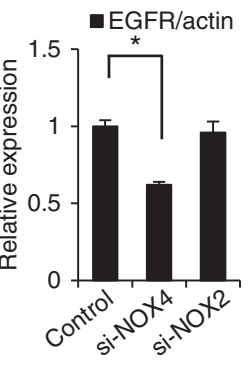

Figure 5. Association of NOX4 and EGFR levels in A549 cells. (A and G) A549 cells were transfected with si-control or with si-NOX4 and were grown in attached or suspended conditions for $24 \mathrm{~h}$, followed by immunoblotting analysis. The levels of EGFR were quantified by a densitometry and normalised to $\beta$-actin levels. The ratio of EGFR to actin in the attached/control cells was set at 1. (B and C) A549 cells were transfected with sicontrol or with si-NOX4 for $24 \mathrm{~h}$. The cells were processed for immunofluorescence analysis (B) or flow cytometry analysis (C). Non-specific lgG was used as a negative control for EGFR staining. (D and F) Mock or NOX4-overexpressing A549 cells were grown in attached or suspended conditions for $24 \mathrm{~h}$, followed by immunoblotting analysis. (E) Mock or NOX4-overexpressing A549 cells were transfected with si-control or with si-NOX4, and then were grown in suspended condition for $24 \mathrm{~h}$, followed by immunoblotting analysis. The levels of EGFR were quantified by a densitometry and normalised to $\beta$-actin levels. The ratio of EGFR to actin was set at 1 either in the Mock/control cells (E) or in the si-control cells $(\mathrm{H})$, respectively. ( $\mathbf{H}$ and I) A549 cells were transfected with si-control, si-NOX4, or si-NOX2 and were grown in suspended conditions for $24 \mathrm{~h}$, followed by immunoblotting analysis (H) or cell imaging (I). Scale bars: $20 \mu \mathrm{m}$ in B. Scale bars: $100 \mu \mathrm{m}$ in I. The data are presented as averages of triplicate measurements with the error bars representing standard deviations $\left({ }^{\star} P<0.05\right)$. Similar results were observed in three independent experiments.

expression is positively linked to EGFR levels. Our data further suggest that NOX4 regulates EGFR at the transcriptional level rather than via the protein degradation pathway, as NOX4 knockdown decreased EGFR at the mRNA level in both attached and suspended cells (supplementary Figure 3). In addition, there was little change in levels of Sprouty2, which inhibits the EGFR degradation pathway (supplementary Figure 3). A previous study showed that EGFR inhibits anoikis via downregulation of the proapoptotic protein Bim (Reginato et al, 2003). We also found that, in ECM-detached conditions, Bim protein levels decreased when NOX4 was overexpressed, whereas Bim protein levels increased when NOX4 was knocked down (Figure 5F). Therefore, it is likely that NOX4 upregulation maintains EGFR levels upon ECM detachment, leading to Bim downregulation and anoikis resistance. 


\begin{tabular}{|c|c|c|c|c|c|}
\hline $\begin{array}{c}\text { Aus per Att } \\
\text { ratio }\end{array}$ & Raw & Control & Genbank & $\begin{array}{c}\text { Gene } \\
\text { symbol }\end{array}$ & Description \\
\hline 0.327 & 118 & 362 & NM_005228 & EGFR & $\begin{array}{c}\text { Epidermal growth factor receptor (erythroblastic } \\
\text { leukaemia viral (v-erb-b) oncogene homolog, avian) }\end{array}$ \\
\hline
\end{tabular}

B

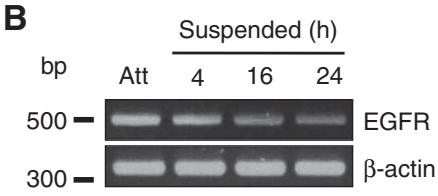

F

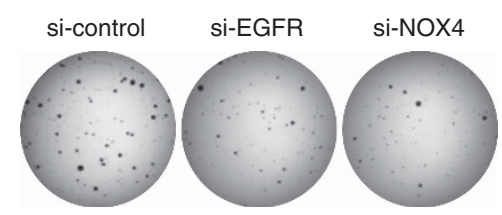

D
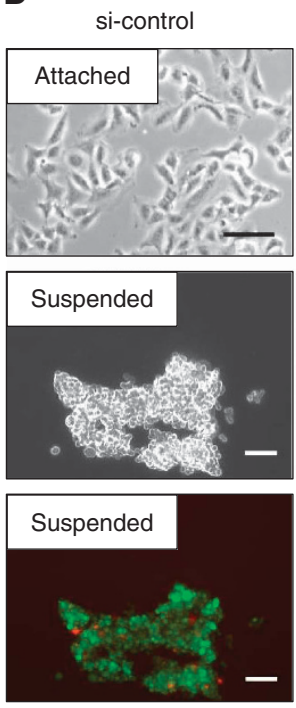

si-EGFR
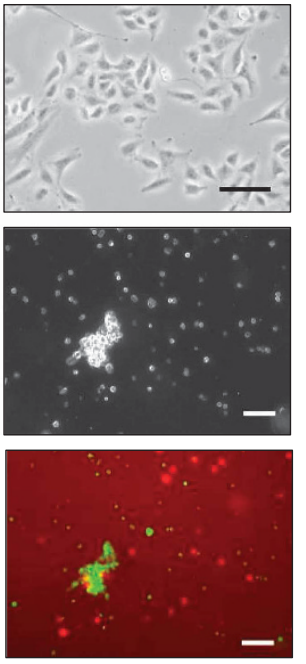

G

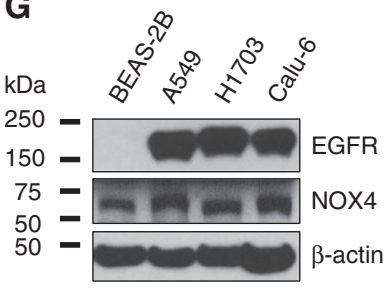

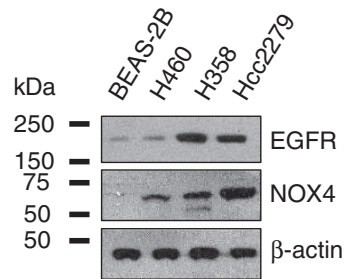

H

$\operatorname{gg}$
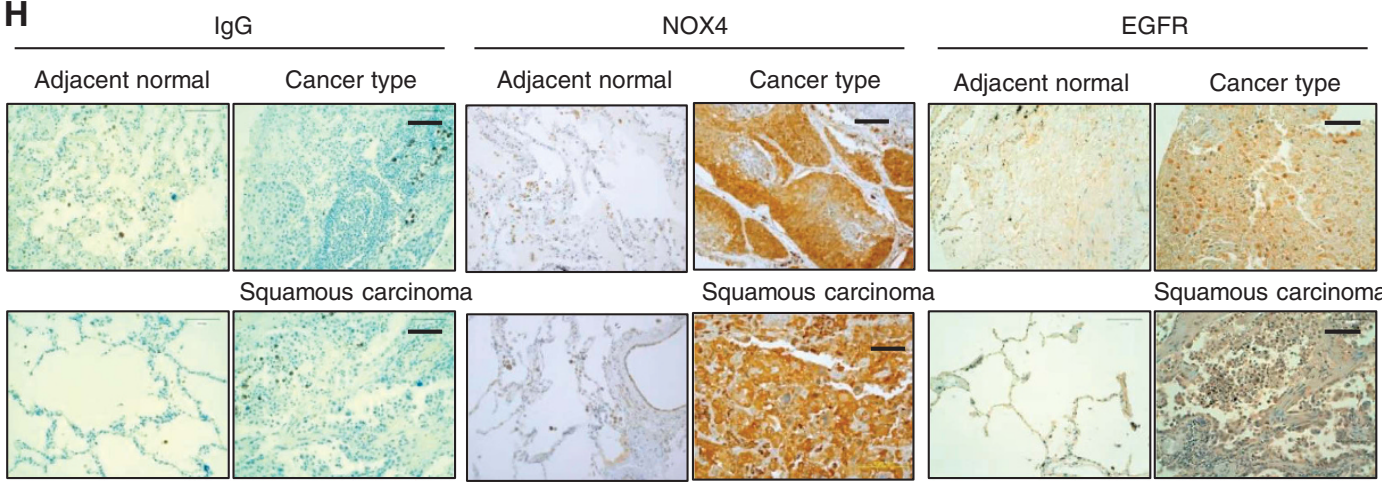

Adenocarcinoma

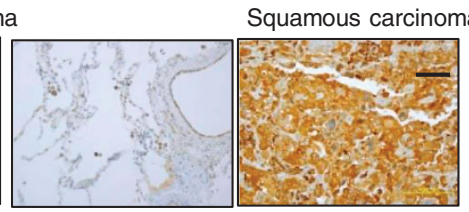

Adenocarcinoma

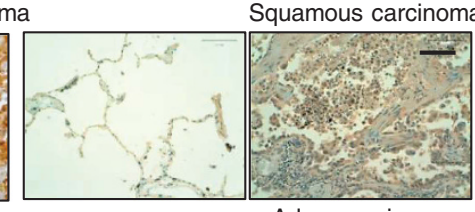

Adenocarcinoma

Figure 6. Association of EGFR levels with anoikis sensitivity in A549 cells. (A) A549 cells were grown in attached or suspended conditions for $24 \mathrm{~h}$, and total RNA was extracted and processed for expression microarray. (B and C) A549 cells were grown in attached or suspended conditions for $24 \mathrm{~h}$ or indicated times, followed by total mRNA extraction for RT-PCR (B) and cell lysate preparation for immunoblotting analysis (C). (D and E) A549 cells were transfected with si-control or si-EGFR RNAs and were grown in attached or suspended conditions for $24 \mathrm{~h}$, followed by cell viability analysis (D) or immunoblotting analysis (E). (F) A549 cells were transfected with si-control, si-EGFR, or si-NOX4, and $1 \times 10^{3}$ cells/well of a 35 mm culture plate were seeded and cultured in soft agar medium for 2 weeks, followed by staining with INT and imaging. (G) Cell lysates from BEAS-2B, A549, H1703, Calu-6, H460, H358 and HCC2270 cell lines were analysed by immunoblotting using anti-EGFR and anti-NOX4 antibodies. Similar results were observed in three independent experiments. (H) A patient-derived lung cancer tissue microarray was examined for NOX4 and EGFR expression using an immunoperoxidase method and isotype lgG was used as a control for staining. The staining results were graded according to intensity and proportion of positive cells described in the 'Materials and Methods' section. 
Table 1. Summary of NOX4 expression and clinicopathological feature in the lung cancer patients

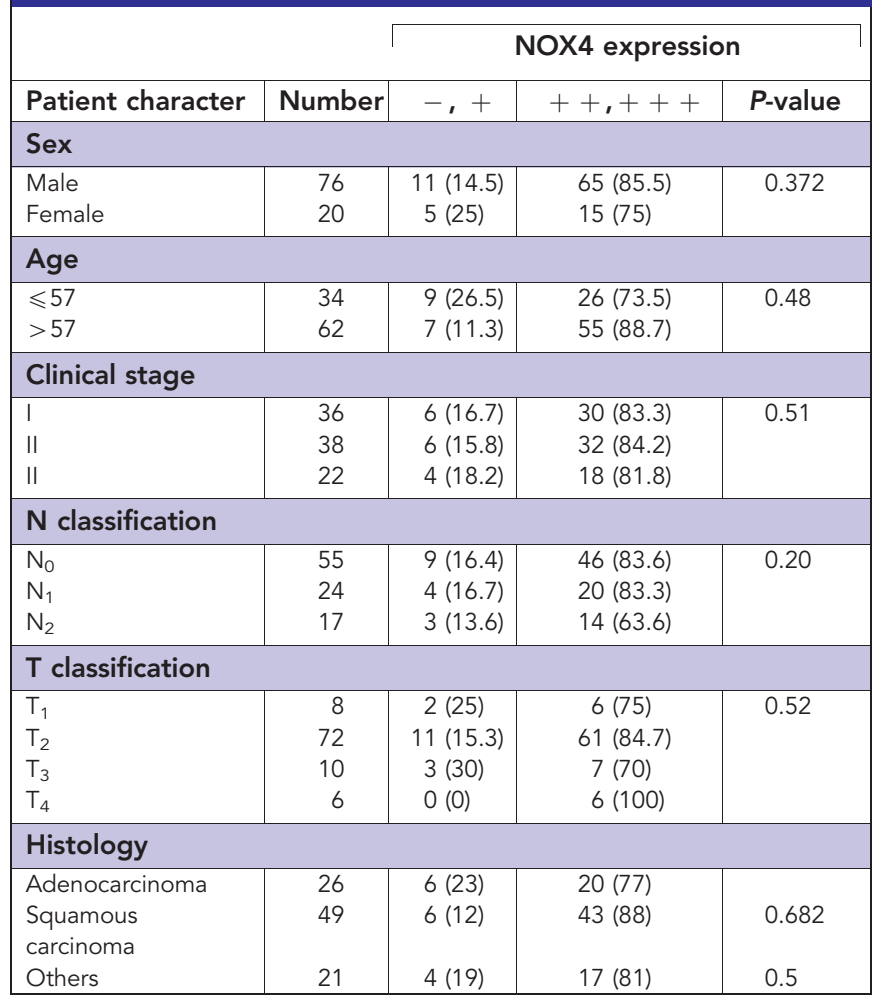

2. Summary of NOX4 and EGFR expression in the lung cancer tissues

\begin{tabular}{|l|c|c|c|}
\cline { 2 - 4 } & \multicolumn{3}{|c|}{ NOX4 expression $(\boldsymbol{P}<0.01)$} \\
\cline { 2 - 4 } & $(-,+)$ & $(++,+++)$ & Total \\
\hline EGFR $(-,+)$ & $14(27.5 \%)$ & $37(72.5 \%)$ & $51(53 \%)$ \\
\hline EGFR $(++,+++)$ & $2(4 \%)$ & $43(96 \%)$ & $45(47 \%)$ \\
\hline Total & $16(17 \%)$ & $80(83 \%)$ & $96(100)$ \\
\hline Abbreviation: EGFR $=$ epidermal growth factor receptor. \\
\hline
\end{tabular}

Several studies indicate that NOX4 is associated with EGFR function. For example, TGF- $\beta$ upregulates NOX4, and this upregulation is important for survival signalling via EGFR transactivation in fetal rat hepatocytes (Murillo et al, 2007). Moreover, angiotensin II induces EGFR transactivation via NOX4 during cardiac hypertrophy (Zeng et al, 2013) and renal tubular cell dedifferentiation (Chen et al, 2012). In addition, the EGFR tyrosine kinase inhibitor erlotinib induces NOX4 upregulation, which mediates cell survival through activation of cytoprotective autophagy or induction of proinflammatory cytokines, including IL-6, in head and neck cancer cells (Sobhakumari et al, 2013). These studies suggest that NOX4 upregulation is associated with cell survival through EGFR modulation. In support of this notion, we demonstrated that NOX4 was upregulated by the unfavorable condition of ECM detachment and that NOX4 was necessary for maintaining EGFR levels and activating EGFR, both of which are critical for anoikis resistance.

Finally, we also showed that knockdown of EGFR or NOX4 in adherent cell culture delayed cell growth but did not induce cell death. However, knockdown of EGFR or NOX4 in suspension cell culture dramatically decreased cell cluster formation and cell survival (Figures 4 and 6), indicating that both molecules are critical for anoikis resistance and tumour progression. Furthermore, our immunocytochemistry analysis using a lung cancer tissue microarray revealed that NOX4 expression was increased in the majority of lung cancer patient samples compared with the adjacent normal tissue samples (Figure $6 \mathrm{H}$ ). Bing Liu's group also recently reported that NOX4 expression is increased in non-small cell lung cancer patients and this result closely correlates with clinical stage and survival time (Zhang et al, 2014). Intriguingly, we found that NOX4 expression is positively correlated with EGFR expression in lung cancer patients (Table 2). It is possible that high levels of NOX4 not only increase ROS levels to enhance cell survival but also increase or maintain high levels of EGFR to enhance tumour progression as illustrated in the model (Supplementary Figure 7). Because it is well known that higher activity of EGFR, via its overexpression or mutation, is associated with cancer progression, it is conceivable that targeting NOX4, and thus disrupting EGFR signalling, is a viable strategy to control cancer progression.

\section{ACKNOWLEDGEMENTS}

This work was supported by National Research Foundation of Korea (NRF) funded by the Ministry of Education, Science and Technology (NRF-2011-0016025) and by National Cancer Center (NCC-1510090).

\section{CONFLICT OF INTEREST}

The authors declare no conflict of interest.

\section{REFERENCES}

Bauer KM, Watts TN, Buechler S, Hummon AB (2014) Proteomic and functional investigation of the colon cancer relapse-associated genes NOX4 and ITGA3. J Proteome Res 13(11): 4910-4918.

Bedard K, Krause KH (2007) The NOX family of ROS-generating NADPH oxidases: physiology and pathophysiology. Physiol Rev 87(1): 245-313.

Block K, Gorin Y (2012) Aiding and abetting roles of NOX oxidases in cellular transformation. Nat Rev Cancer 12(9): 627-637.

Bonner MY, Arbiser JL (2012) Targeting NADPH oxidases for the treatment of cancer and inflammation. Cell Mol Life Sci 69(14): 2435-2442.

Boudreau HE, Casterline BW, Rada B, Korzeniowska A, Leto TL (2012) Nox4 involvement in TGF-beta and SMAD3-driven induction of the epithelialto-mesenchymal transition and migration of breast epithelial cells. Free Radic Biol Med 53(7): 1489-1499.

Buchheit CL, Weigel KJ, Schafer ZT (2014) Cancer cell survival during detachment from the ECM: multiple barriers to tumour progression. Nat Rev Cancer 14(9): 632-641.

Chang CC, Yang MH, Lin BR, Chen ST, Pan SH, Hsiao M, Lai TC, Lin SK, Jeng YM, Chu CY, Chen RH, Yang PC, Chin YE, Kuo ML (2013) CCN2 inhibits lung cancer metastasis through promoting DAPKdependent anoikis and inducing EGFR degradation. Cell Death Differ 20(3): 443-455.

Chen J, Chen JK, Harris RC (2012) Angiotensin II induces epithelial-tomesenchymal transition in renal epithelial cells through reactive oxygen species/Src/caveolin-mediated activation of an epidermal growth factor receptor-extracellular signal-regulated kinase signaling pathway. Mol Cell Biol 32(5): 981-991.

Ding Y, Chen ZJ, Liu S, Che D, Vetter M, Chang CH (2005) Inhibition of Nox-4 activity by plumbagin, a plant-derived bioactive naphthoquinone. J Pharm Pharmacol 57(1): 111-116.

Edderkaoui M, Nitsche C, Zheng L, Pandol SJ, Gukovsky I, Gukovskaya AS (2011) NADPH oxidase activation in pancreatic cancer cells is mediated through Akt-dependent up-regulation of p22phox. J Biol Chem 286(10): 7779-7787. 
Frisch SM, Schaller M, Cieply B (2013) Mechanisms that link the oncogenic epithelial-mesenchymal transition to suppression of anoikis. J Cell Sci 126(Pt 1): 21-29.

Giannoni E, Buricchi F, Grimaldi G, Parri M, Cialdai F, Taddei ML, Raugei G, Ramponi G, Chiarugi P (2008) Redox regulation of anoikis: reactive oxygen species as essential mediators of cell survival. Cell Death Differ 15(5): $867-878$.

Giannoni E, Chiarugi P (2014) Redox circuitries driving Src regulation. Antioxid Redox Signal 20(13): 2011-2025.

Giannoni E, Fiaschi T, Ramponi G, Chiarugi P (2009) Redox regulation of anoikis resistance of metastatic prostate cancer cells: key role for Src and EGFR-mediated pro-survival signals. Oncogene 28(20): 2074-2086.

Grassian AR, Schafer ZT, Brugge JS (2011) ErbB2 stabilizes epidermal growth factor receptor (EGFR) expression via Erk and Sprouty2 in extracellular matrix-detached cells. J Biol Chem 286(1): 79-90.

Gregg JL, Turner 2nd RM, Chang G, Joshi D, Zhan Y, Chen L, Maranchie JK (2014) NADPH oxidase NOX4 supports renal tumorigenesis by promoting the expression and nuclear accumulation of HIF2alpha. Cancer Res 74(13): 3501-3511.

Hiraga R, Kato M, Miyagawa S, Kamata T (2013) Nox4-derived ROS signaling contributes to TGF-beta-induced epithelial-mesenchymal transition in pancreatic cancer cells. Anticancer Res 33(10): 4431-4438.

Hsieh CH, Chang HT, Shen WC, Shyu WC, Liu RS (2012) Imaging the impact of Nox4 in cycling hypoxia-mediated U87 glioblastoma invasion and infiltration. Mol Imag Biol 14(4): 489-499.

Hsieh CH, Shyu WC, Chiang CY, Kuo JW, Shen WC, Liu RS (2011) NADPH oxidase subunit 4-mediated reactive oxygen species contribute to cycling hypoxia-promoted tumor progression in glioblastoma multiforme. PLoS One 6(9): e23945.

Kim YN, Koo KH, Sung JY, Yun UJ, Kim H (2012) Anoikis resistance: an essential prerequisite for tumor metastasis. Int J Cell Biol 2012: 306879.

Lassegue B, Griendling KK (2010) NADPH oxidases: functions and pathologies in the vasculature. Arterioscler Thromb Vasc Biol 30(4): 653-661.

Lee SH, Koo KH, Park JW, Kim HJ, Ye SK, Park JB, Park BK, Kim YN (2009) HIF-1 is induced via EGFR activation and mediates resistance to anoikislike cell death under lipid rafts/caveolae-disrupting stress. Carcinogenesis 30(12): 1997-2004.

Mondol AS, Tonks NK, Kamata T (2014) Nox4 redox regulation of PTP1B contributes to the proliferation and migration of glioblastoma cells by modulating tyrosine phosphorylation of coronin-1C. Free Radic Biol Med 67: 285-291.

Murillo MM, Carmona-Cuenca I, Del Castillo G, Ortiz C, Roncero C, Sanchez A, Fernandez M, Fabregat I (2007) Activation of NADPH oxidase by transforming growth factor-beta in hepatocytes mediates up-regulation of epidermal growth factor receptor ligands through a nuclear factor-kappaBdependent mechanism. Biochem J 405(2): 251-259.

Paoli P, Giannoni E, Chiarugi P (2013) Anoikis molecular pathways and its role in cancer progression. Biochim Biophys Acta 1833(12): 3481-3498.

Peus D, Vasa RA, Meves A, Pott M, Beyerle A, Squillace K, Pittelkow MR (1998) H2O2 is an important mediator of UVB-induced EGF-receptor phosphorylation in cultured keratinocytes. J Invest Dermatol 110(6): 966-971.
Reginato MJ, Mills KR, Paulus JK, Lynch DK, Sgroi DC, Debnath J, Muthuswamy SK, Brugge JS (2003) Integrins and EGFR coordinately regulate the pro-apoptotic protein Bim to prevent anoikis. Nat Cell Biol 5(8): 733-740.

Shimada K, Fujii T, Anai S, Fujimoto K, Konishi N (2011) ROS generation via NOX4 and its utility in the cytological diagnosis of urothelial carcinoma of the urinary bladder. BMC Urol 11: 22 .

Sobhakumari A, Schickling BM, Love-Homan L, Raeburn A, Fletcher EV, Case AJ, Domann FE, Miller Jr FJ, Simons AL (2013) NOX4 mediates cytoprotective autophagy induced by the EGFR inhibitor erlotinib in head and neck cancer cells. Toxicol Appl Pharmacol 272(3): 736-745.

Sung JY, Park SY, Kim JH, Kang HG, Yoon JH, Na YS, Kim YN, Park BK (2014) Interferon consensus sequence-binding protein (ICSBP) promotes epithelial-to-mesenchymal transition (EMT)-like phenomena, cellmotility, and invasion via TGF-beta signaling in U2OS cells. Cell Death Dis 5: e1224.

Taddei ML, Giannoni E, Fiaschi T, Chiarugi P (2012) Anoikis: an emerging hallmark in health and diseases. J Pathol 226(2): 380-393.

Tebbutt N, Pedersen MW, Johns TG (2013) Targeting the ERBB family in cancer: couples therapy. Nat Rev Cancer 13(9): 663-673.

Vaquero EC, Edderkaoui M, Pandol SJ, Gukovsky I, Gukovskaya AS (2004) Reactive oxygen species produced by $\mathrm{NAD}(\mathrm{P}) \mathrm{H}$ oxidase inhibit apoptosis in pancreatic cancer cells. J Biol Chem 279(33): 34643-34654.

Weyemi U, Caillou B, Talbot M, Ameziane-El-Hassani R, Lacroix L, Lagent-Chevallier O, Al Ghuzlan A, Roos D, Bidart JM, Virion A, Schlumberger M, Dupuy C (2010) Intracellular expression of reactive oxygen species-generating NADPH oxidase NOX4 in normal and cancer thyroid tissues. Endocr Relat Cancer 17(1): 27-37.

Yamaura M, Mitsushita J, Furuta S, Kiniwa Y, Ashida A, Goto Y, Shang WH, Kubodera M, Kato M, Takata M, Saida T, Kamata T (2009) NADPH oxidase 4 contributes to transformation phenotype of melanoma cells by regulating G2-M cell cycle progression. Cancer Res 69(6): 2647-2654.

Zeng SY, Chen X, Chen SR, Li Q, Wang YH, Zou J, Cao WW, Luo JN, Gao H, Liu PQ (2013) Upregulation of Nox4 promotes angiotensin II-induced epidermal growth factor receptor activation and subsequent cardiac hypertrophy by increasing ADAM17 expression. Can J Cardiol 29(10): 1310-1319.

Zhang C, Lan T, Hou J, Li J, Fang R, Yang Z, Zhang M, Liu J, Liu B (2014) NOX4 promotes non-small cell lung cancer cell proliferation and metastasis through positive feedback regulation of PI3K/Akt signaling. Oncotarget 5(12): 4392-4405.

Zhang Y, Lu H, Dazin P, Kapila Y (2004) Squamous cell carcinoma cell aggregates escape suspension-induced, p53-mediated anoikis: fibronectin and integrin alphav mediate survival signals through focal adhesion kinase. J Biol Chem 279(46): 48342-48349.

This work is published under the standard license to publish agreement. After 12 months the work will become freely available and the license terms will switch to a Creative Commons AttributionNonCommercial-Share Alike 4.0 Unported License.

Supplementary Information accompanies this paper on British Journal of Cancer website (http://www.nature.com/bjc) 